\title{
Proper Hand Washing for School Children
}

Germs can hide under long fingernails and on dirty hands. Keeping your fingernails short and washing your hands often, are the most important things you can do to stop germs from making you sick. Germs that cause illnesses such as colds, flu, diarrhea, and vomiting can get on your hands from touching things around you. People, pets, raw foods, toys, soil, and objects used in our daily lives can all have germs on them. When you wash your hands properly it helps remove germs from your hands.

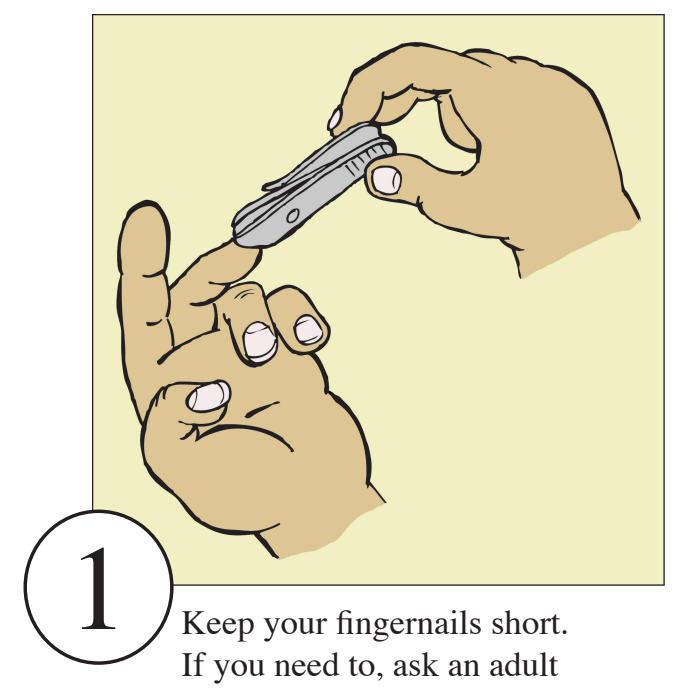

for help cutting fingernails.
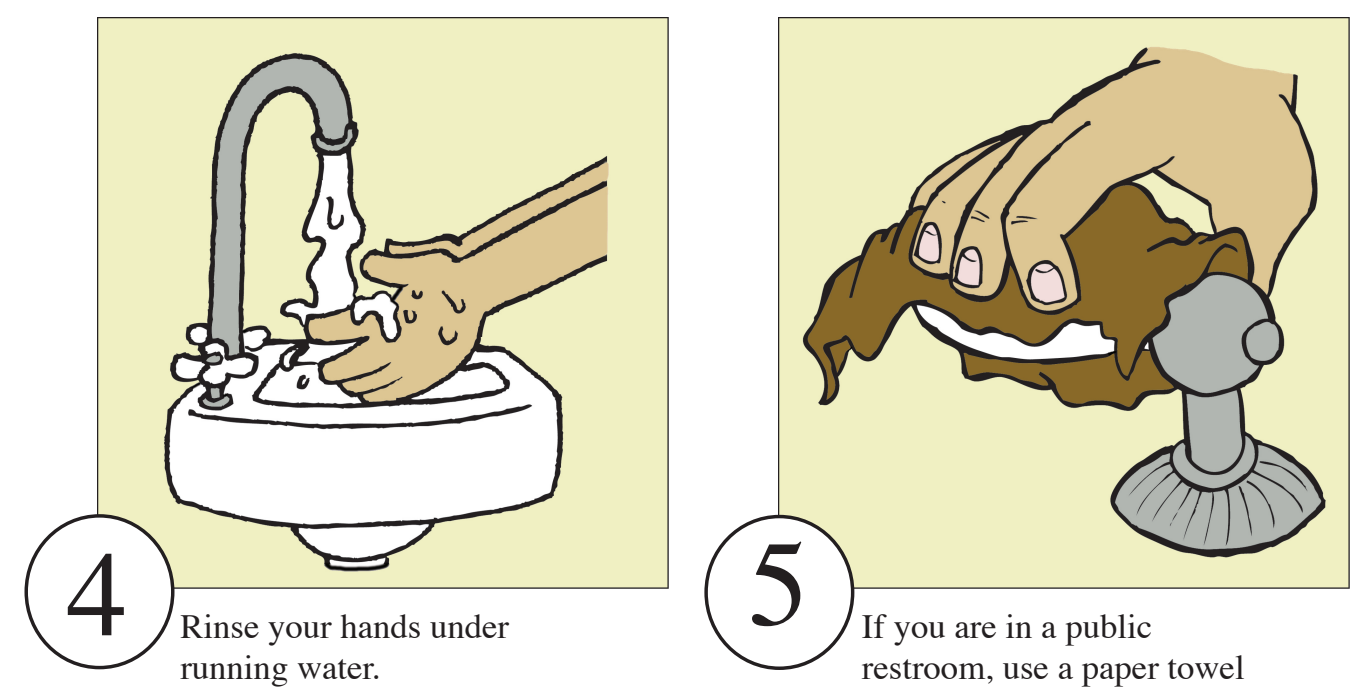

to turn off the water.
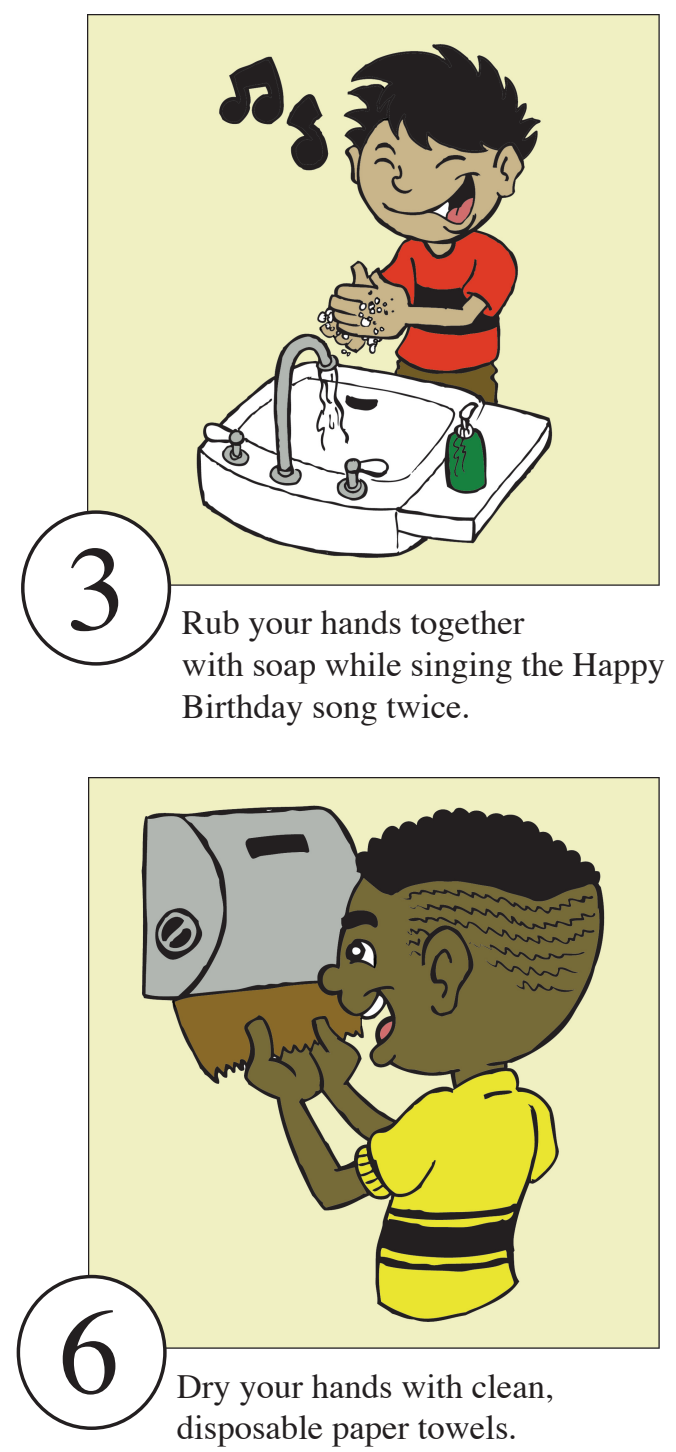

\section{Wash your hands before:}

- Eating and snacking

- Drinking

- Preparing foods

- Touching your mouth
Wash your hands after:

- Visiting the restroom

- Coughing or sneezing on your hands

- Playing outdoors

- Handling pets

- Doing other activities that dirty your hands

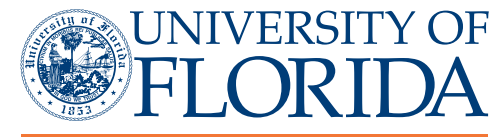

IFAS EXTENSION
Author: Amy Simonne, Ph.D., assistant professor, Family, Youth and Community Science, Cooperative Extension Service, Institute of Food and Agricultural Sciences, University of Florida, Gainesville, FL 32611. Jason Green, illustrator. Hope D. Norman, designer. 